\title{
An evaluation of BMI and the Healthy Working Lives Initiative on workplace physical activity levels (the NeuroFAST study)
}

\author{
L B. Kirwan ${ }^{1}$, A.M. Johnstone ${ }^{2}$ and C.L. Fyfe ${ }^{2}$ \\ ${ }^{1}$ University College Dublin, Belfield, Dublin 4, Ireland and ${ }^{2}$ The Rowett Institute of Nutrition and Health, University of \\ Aberdeen, AB25 2ZD, UK
}

UK physical activity levels have declined by $20 \%$ in the last 50 year and are expected to decline by a further $15 \%$ by 2030 . It is predicted that by 2030, if not addressed, the average individual in the UK will only use $25 \%$ more energy than they would have had, had they stayed in bed ${ }^{1}$. The aim of the present study was to analyse previously collected data (NeuroFAST, www.neurofast.net) in relation to BMI, physical activity (PA) levels and the workplace Healthy Working Lives (HWL) initiative. 305 free-living public sector workers were recruited in total. Workplace one consisted of Aberdeen College and the University of Aberdeen staff, which have the HWL initiative $\left(n=150,41\right.$ male, 109 female) with a mean $( \pm$ SEM) age of $40 \cdot 8 \pm 0 \cdot 9 \mathrm{yrs}$ (range $19-65 \mathrm{yrs})$ and $\mathrm{BMI} 24 \cdot 8 \pm 0 \cdot 3 \mathrm{~kg} / \mathrm{m}^{2}$ (range $15.9-39.1 \mathrm{~kg} / \mathrm{m}^{2}$ ). Workplace two consisted of staff from Aberdeen city and Aberdeenshire secondary schools with no HWL initiative $\left(\mathrm{n}=155,42\right.$ male, 113 female) and had a mean $( \pm$ SEM) age of $44 \cdot 1 \pm 0.9 \mathrm{yrs}$ (range $22-68 \mathrm{yrs})$ and $\mathrm{BMI} 26 \cdot 4 \pm 0.4 \mathrm{~kg} / \mathrm{m}^{2}$ (range $17 \cdot 3-60 \cdot 0 \mathrm{~kg} / \mathrm{m}^{2}$ ). Workplace activity levels were assessed for 7 consecutive days by triaxial accelerometry (ActiGraph LLC, USA). PA behaviours were compared to establish whether the HWL initiative implemented was positively influencing staff PA behaviour. We report that normal weight subjects took more steps/day than overweight or obese subjects; Mean ( \pm SEM) steps were $9,321 \pm 263,8,779 \pm 273$ and 7,299 \pm 292 for normal weight, overweight and obese subjects respectively $(\mathrm{p}<0 \cdot 001)$. Obese subjects expended more energy than overweight and normal weight subjects; Mean EE ( \pm SEM) was 1,292 $\pm 38,1,636 \pm 59$ and 2,007 \pm $94 \mathrm{kcal}$ for normal weight, overweight and obese subjects respectively $(\mathrm{p}<0.001)$. Statistically significant differences in hours worked between BMI groups were found, with overweight participants showing the highest mean hours worked ( $44.0 \mathrm{hrs} / \mathrm{wk}$ ). There were no significant differences observed in PA levels between workplaces with and without the HWL initiative as assessed by accelerometry (steps and activity levels). There were also no statistical differences by age, BMI, gender or workplace for the total number of hours worked or hours slept. The HWL initiative was therefore deemed ineffective in relation to improving PA levels in the workplaces evaluated. Overweight BMI was associated with longer working hours with activity level and BMI inversely related. The mere implementation of a generic health intervention may be insufficient in improving activity levels in the workplace. In order for workplace health inequalities to be addressed; targeted workplace interventions need to be developed and monitored to ensure long-term success.

The work is funded by the Scottish Government and European Union Seventh Framework Programme (FP7/2007-2013) under grant agreement $\mathrm{n}^{\circ} 245009$ for the 'NeuroFAST' grant.

1 UKActive (2014) http://ukactive.com/downloads/managed/Turning_the_tide_of_inactivity.pdf 